\title{
REEXAMINING THE CRITICAL PERIOD HYPOTHESIS
}

\section{A Case Study of Successful Adult SLA in a Naturalistic Environment}

\author{
Georgette loup \\ University of New Orleans
}

\section{Elizabeth Boustagui}

Arab Maritime Transport Academy

\author{
Manal El Tigi and Martha Moselle \\ American University in Cairo
}

\begin{abstract}
This study concerns the ability of adults to achieve nativelike competence in second language when the acquisition context lacks formal instruction and, therefore, more closely resembles the environment for first language acquisition. The study presents the results of extensive testing of an adult who has apparently acquired native proficiency in Egyptian Arabic (EA) in an untutored setting. The goal is to determine to what extent her linguistic competence matches that of native speakers. Measures employed to assess her level of achievement are a speech production task, a grammaticality judgment task, a translation task, an anaphoric interpretation task, and an accent recognition task. Results are compared to those of native speakers as well as to those of a proficient learner of EA with extensive formal instruction. The results lead the authors to reexamine the critical period
\end{abstract}

The authors would like to thank John Aydelott, Ali Farghaly, Loraine Obler, William Rutherford, and the anonymous reviewers for their invaluable comments and suggestions on an earlier draft of the article.

An earlier version of this paper was presented at the 14th Annual Meeting of the American Association for Applied Linguistics, Seattle, March 1992.

Address correspondence to Georgette Ioup, Department of English, University of New Orleans, New Orleans, LA 70148. 


\begin{abstract}
hypothesis while addressing the role of talent in adult language learning. The study concludes with an evaluation of our subject's language learning history to discover what factors differentiate her from less successful naturalistic adult acquirers.
\end{abstract}

The present study examines the linguistic competence of an adult second language (L2) learner of Egyptian Arabic (EA) who was first exposed to the target language after the close of the critical period. Julie, the subject of this study, is unusual in that she appears to have acquired nativelike proficiency in an untutored learning context. To determine her level of achievement more precisely, her performance on various linguistic measures is compared to that of both a highly proficient tutored learner of EA and native speakers. The results allow for a reexamination of the critical period hypothesis $(\mathrm{CPH})$ and its more recent formulation in the maturational state hypothesis (Long, 1990). In addition, they address the nature of exceptional language learning.

The CPH was initially proposed by Penfield and Roberts (1959) and later refined by Lenneberg (1967) to account for the difficulty of acquiring first language (L1) after 9-12 years of age. Empirical evidence for the critical period was found through cases of feral children who failed to completely acquire L1 after the onset of puberty and of aphasics who were unable to fully recover their language if the brain lesion was postpubertal.

Many researchers have examined the applicability of the CPH to L2 acquisition. The term sensitive period has been proposed as a means of indicating that the critical period is not an abrupt or absolute criterion after which $L 2$ acquisition is impossible but rather a gradual process within which the ultimate level of L2 attainment becomes variable. Within this framework researchers have proposed the maturational state hypothesis (Long, 1990), which predicts that not only will there be differences between children and adults acquiring $\mathrm{Ll}$, but also children learning $\mathrm{L} 2$ will find their task easier than adults. By extension, adults will fail to reach a uniform nativespeaker standard in different skill areas, including phonology, morphology, syntax, lexis, and pragmatic features. It may be true that adults initially out-perform children in their rate of $\mathrm{L} 2$ acquisition; however, children do better than adults in ultimate attainment. Thus, ultimate attainment becomes the main criterion for supporting or refuting the concept of a sensitive period for $\mathrm{L} 2$ acquisition.

In general, the idea of a sensitive period for $L 2$ acquisition is supported through both experimental and case studies examining the bilingual performance of adults and revealing their failure to attain nativelike levels in the L2. Several large-scale experimental studies comparing younger and older learners with long-term residence report age effects favoring the younger learners in the domains of phonology, syntax, and semantics (Johnson \& Newport, 1989; Oyama, 1976; Patkowski, 1980). Coppieters (1987) found that older arriving learners with near-native ability continue to exhibit problems in the domains of both syntax and discourse semantics, while Scarcella (1983) determined that fluent bilinguals who began L2 as older children 
still retain nonnative features in the domain of discourse pragmatics. The results of these and similar studies led Long (1990) to issue a challenge to researchers to find one successful learner who would refute the sensitive period hypothesis.

However, several researchers dispute the conclusions of the preceding studies (Flege, 1987; Genesee, 1988) or find counterevidence in research of their own (Birdsong, 1992; Flynn \& Manuel, 1991; Neufeld, 1978, 1979), leading them to challenge the notion of a sensitive period for $\mathrm{L} 2$ acquisition. As a result of the conflicting data and the difficulty in determining when a learner has, in fact, achieved a nativespeaker standard, the status of the $\mathrm{CPH}$ with respect to $\mathrm{L} 2$ acquisition remains in doubt.

An issue not addressed by those discussing the $\mathrm{CPH}$ is the place of exceptional learners within the hypothesis. The $\mathrm{CPH}$ is based on neuropsychological factors, the most important of which is brain maturation. A common opinion is that as the human brain matures, the cognitive structures that allow for automatic language acquisition in the child deteriorate. Since all adults who possess $\mathrm{L} 1$ are capable of acquiring some degree of $L 2$, one must explain first why this is possible at all and then why $\mathrm{L} 2$ acquisition in the mature organism is not as successful as L1 acquisition. Bley-Vroman (1990) argues that older learners no longer have access to their innate language acquisition mechanism, consisting of the principles of Universal Grammar (UG) (Chomsky, 1981) and language-specific learning procedures. Instead, adult language learning is achieved through the assistance of $\mathrm{Ll}$ knowledge interacting with general learning principles. Others who espouse some version of this theory are Clahsen (1990) and Schachter (1989).

Other researchers argue that UG is fully accessible to the adult $\mathrm{L} 2$ acquirer but offer alternative explanations for the diminished attainment. Felix (1985) posits a set of problem-solving cognitive structures that develop at puberty and compete with the language-specific cognitive structures in analyzing L2 input data. The diminished language acquisition skills observed in adults result from the inappropriate application of these competing learning procedures to portions of the L2 data. Flynn (1989) and White $(1989,1992)$, also arguing for an intact UG in adult learners, focus on the role of the L1 in the L2 acquisition process. They attribute the difficulties of the older learner to an inability to reset the parameters for the L2, relying instead on the settings for the L1. They maintain that with time the adult learner will be able to reset the parameters correctly but may require negative evidence to do so.

None of these views of adult language learning accounts for the exceptional adult who manages to acquire L2 to a native or near-native level of proficiency. In general, discussions of age effects in language acquisition do not consider the role of talent or aptitude in adult language learning. A different research paradigm has served to relate success in L2 acquisition to the notion of talent. Schneiderman and Desmarais (1988b) define talent as neurocognitive flexibility, in the sense that talented learners do not process $\mathrm{L} 2$ input in terms of the rigid parameters they have set for $\mathrm{L} 1$ but, rather, are flexible enough to set new parameters or neural pathways for L2. The researchers distinguish between two types of talent: one related to grammar and lexis, and the other to accent. After examining two talented adult language learners, they conclude that talent implies bilateral processing and high associative memory. 
Similar results have been found by Novoa, Fein, and Obler (1988) in a study of CJ, another talented learner.

One difficulty with the explanation of talent as the ability to succeed initially at setting the parameters for $\mathrm{L} 2$ is that parameter setting concerns only core grammar, that is, those aspects of language determined by UG. A large number of rules in a language involve the periphery, the language-specific constructs that can be equally troubling to the adult L2 learner. Morphology is one area of the periphery that the child can master easily but that tends to elude the adult learner, especially one not exposed to formal instruction (cf. Schmidt, 1983). The exceptional learners reported in the literature appear to have mastered the majority of the language-specific aspects of the $L 2$, including those pertaining to the morphology. A parameter-setting explanation cannot fully account for their success.

The role of language aptitude in language acquisition is addressed by Carroll $(1965,1991)$ and Skehan $(1986,1993)$. Aptitude is typically discussed with reference to successful language learners within a classroom setting. Carroll (1965) originally defined the construct as consisting of four components, but Skehan $(1986,1993)$ has collapsed them into three: auditory ability, linguistic ability, and memory ability. Auditory ability is the capacity to process the new sound system. Linguistic ability consists of grammatical sensitivity and the capacity for inducing linguistic generalizations from the data. Memory ability pertains to the retention of both lexical material and analyzed rule structure. The three components of aptitude relate to three stages of learning new language material: processing the input data, analyzing it, and storing it. Testing has shown that some successful learners are those with great linguistic sensitivity while others are those with exceptional memories, although some are superior in both areas (Skehan, 1986).

A problem with aptitude studies is the imprecise definition of the term success. Aptitude is measured by correlating scores on aptitude tests with scores on proficiency measures. It is shown that those performing well on the proficiency measures are also those who score high on some or all of the aptitude measures, thus giving validity to the construct of aptitude. However, in identifying successful learners as those at the high end of a proficiency continuum, measures of aptitude do not single out exceptional learners, those few adults who seem to achieve nativelike competence, from those who are simply better than the average learner. In this respect the study of aptitude differs from the study of talent.

The relationship between talent and the ability to attain a nativelike level in the $\mathrm{L} 2$ is implicit, in as much as the preceding studies do not document whether the talented learners had attained native-speaker standards and, if so, in what domains of the L2. ${ }^{1}$ In addition, studies of the talented learner have focused on learners who have received some degree of formal instruction in the L2. To date, no study of talent has investigated whether an exceptional adult learner can achieve native or near-native proficiency without formal instruction. Therefore, in order to address gaps and contradictory views related to adult language learning, the present study compares the phonological and syntactic intuitions of native and nonnative speakers of Egyptian Arabic, as a means of addressing the following research questions: 
1. How does the linguistic competence of a talented untutored adult L2 learner compare with that of native speakers?

2. Do tutored and untutored L2 learners who achieve near-native levels of proficiency exhibit similar achievement in the various domains of grammar?

\section{THE SUBJECT OF THE STUDY}

The subject of this study is Julie. Unlike most naturalistic learners reported in the literature, she has been able to achieve nativelike fluency from what Krashen (1982) terms acquisition alone. She has never had formal instruction in Arabic and, therefore, can neither read nor write the language. Julie immigrated to Cairo from Britain at the age of 21 when she married an Egyptian. Nine days after her arrival, her husband was unexpectedly called to military service and she was left with nonEnglish-speaking relatives for 45 days. Since there was no one to assist her in English, she relied on context and gesture to interpret utterances and express meaning. Thus, at this initial stage her language acquisition situation resembled the environment for child $\mathrm{L} 1$ acquisition.

Forty-five days later, when her husband returned, English became the language of daily use. Arabic continued to be used outside the home for casual encounters and at weekly family gatherings. One year after her arrival, Julie took a position as an English teacher in an Egyptian school where she conversed with monolingual colleagues in Arabic. At that point she again began to receive extensive quality input on a daily basis. Beginning with her 3rd year of stay, Arabic again became the home language because at this point her fluency was sufficiently developed to permit her to converse comfortably in the L2. At the time of the study, she had lived in Egypt 26 years and was working as an ESL teacher/trainer at the university level. She has two children who are bilingual, but Arabic has remained the home language.

In terms of her process of acquisition, Julie recalls the following points. To facilitate her communication during her early total immersion, she kept a copy book in which she wrote what she observed concerning the language. At first her notations were unanalyzed wholes with attempts at guessing meanings. Soon she began to keep separate pages for nouns, verbs, and adjectives. Lexical meaning was the main priority, but some elements of inflectional morphology were noted, especially changes involving gender, number, and person. The copy book was kept for 3-4 months. She remembers that fixed expressions and idioms were the most salient items in that early stage of acquisition and were used frequently to enhance communication.

Explicit feedback was received when her errors hampered communication. Feedback usually took the form of corrected or expanded repetitions. Julie recalls that she would make mental or written note of the point of the correction. When she had questions about the language, she saved them until her husband's return from the military. As for her own attitude toward the corrections, these were not a source of inhibition but, rather, greatly appreciated. She maintains that effective communication was her only goal; therefore, she was not concerned with grammar 
except as a means to achieve this end. The errors in her output did not bother her except when they hindered communication. However, she realized that grammatical correctness would facilitate the expression of meaning.

In terms of language or culture shock, Julie reports that this initial period was extremely difficult, as she understood neither the code nor the culture. Her longing for English was so great that she even took to repeated readings of the back of a detergent box. ${ }^{2}$

In spite of the trauma of this initial period, Julie acquired Arabic very quickly. Within $\mathbf{4 5}$ days she was using simple sentences and fixed expressions. By the end of 6 months, she was communicating rather well. After $21 / 2$ years she was able to pass as a native speaker. ${ }^{3}$

With respect to the acquisition of the different domains of the grammar, she reports that phonology was no problem, even initially, as she has a talent for mimicking accents. Her strategy was one of imitation rather than an analytic approach to the sound system. She easily perceived and reproduced the difficult Arabic pharyngeals and uvulars. Though she produced the velarized consonants, she was unaware of their phonemic status until she noticed the alphabetic characters for them in her children's schoolbooks 7 years later.

Arabic is a highly inflected language with complex morphological processes for forming nouns, verbs, and adjectives. A change in inflection not only involves morphological affixation, but also will affect the stress pattern of the word and the addition of epenthetic vowels. The morphophonemic rules that cause phonological adjustments are highly complex and very productive. They are especially relevant to verb cliticization. Julie mastered them without being consciously aware of the phonotactics involved. As to the acquisition of the morphemes themselves, those which Julie consciously noted were the inflections and clitics pertaining to gender, number, and person. She maintains that occasional gender errors and less common irregular plural forms are her only remaining morphological problems. These can also be problem areas for native speakers.

The complex rules of syntax were acquired without conscious attention to form. Even tense distinctions were not consciously noted. Julie reports that she is not sure how she mastered syntactic aspects of the grammar, but somehow they just came. However, as was noted earlier, Julie did respond to negative input, which most likely contained significant feedback on selected syntactic structures.

The domain of achievement that sets Julie apart from other near-native Egyptian Arabic speakers is her manipulation of discourse structure. The Egyptian dialect of Arabic is distinct in its abundant use of specialized discourse markers and pause fillers. The variety of forms and subtle rules of usage for each one make mastery of them difficult even for speakers of other dialects of Arabic. Yet it appears that Julie has been able to gain native control of them. This has been reported anecdotally by native speakers who interact with her. It was also a distinguishing characteristic of her performance on the production task discussed later. She uses conventionalized language of the type described in Yorio (1989). Yorio argues that it is the absence of conventionalized language that distinguishes $\mathrm{L} 2$ learners from native speakers. Julie 
not only uses conventionalized forms but also has been observed to manipulate them so as to correctly produce different social registers.

To summarize the extent of her achievement in EA, Julie has no noticeable foreign accent, makes few mistakes in morphology and syntax, has good control of the lexicon, including conventionalized forms, and appears to have sophisticated discourse competence.

\section{EVALUATION OF JULIE'S LINGUISTIC COMPETENCE}

Is Julie an exception to the CPH? The question cannot be answered without determining her knowledge of those aspects of grammar that do not necessarily appear in her performance. It is necessary to probe her intuitions on more remote properties of the language. Julie was assessed in three areas: the quality of her speech productions, her ability to recognize accents, and her knowledge of syntactic rules for which she may not have received explicit feedback. Her performance in these three areas was compared to both native speakers and a proficient L2 learner who began learning Arabic in a formal setting. Would Julie exhibit the same level of achievement as an instructed learner in each domain tested? Laura was selected for comparison because she was reported to have achieved a nativelike level of proficiency in EA with the aid of formal instruction.

Laura is an American who is married to an Egyptian and is living in Cairo. She had many years of formal instruction in standard Arabic before beginning the study of EA. She commenced the study of standard Arabic during her senior year as an undergraduate, continuing it in France for 2 years after graduation. After a 1-year sojourn in Morocco, where she taught English and acquired the rudiments of Moroccan Arabic, she returned to the United States to obtain a master's degree in modern standard Arabic. She then commenced a Ph.D. in the language, working at the same time as an Arabic teaching assistant. Because she could read but not converse in Arabic, she interrupted her doctoral program to study the spoken Egyptian dialect at the American University in Cairo. She remained in Cairo after her program ended, married an Egyptian, and became a teacher of standard Arabic. Thus, her first exposure to both the written and spoken dialects was in the classroom as an adult, and she has extensively studied both varieties. At the time of the study, Laura had lived in Egypt 10 years and was teaching standard Arabic at the university level.

\section{Speech Production}

The first procedure in the study evaluated the two subjects' spoken language to determine if, in fact, they would be considered native speakers by Egyptian judges. Spontaneous speech was elicited by asking subjects to detail their favorite recipe on tape. ${ }^{4}$ Five other female speakers also performed the task. Three were educated native speakers of the Cairene dialect of Arabic; the other two were very fluent nonnative speakers who were long-time residents of Cairo but who, nevertheless, 
retained noticeable nonnative features in their speech. Judges for the task were 13 teachers of Arabic as a foreign language. They were asked to decide whether or not each speaker was a native Egyptian and to state their reasons for any negative judgments given. ${ }^{5}$ We were interested in learning whether our subjects would be grouped with the native or nonnative speakers.

All judges correctly categorized the three native-speaking and the two nonnativespeaking distractors as native and nonnative, respectively. Julie and Laura were rated as native speakers by 8 of the 13 judges (62\%), with 6 judges considering them both to be nativelike and 2 rating one but not the other as a native speaker. Comments made by judges who gave nonnative ratings focused on some element of pronunciation. With respect to Julie, they stated that though they were initially inclined to rate her as a native speaker, an occasional incorrect pronunciation of certain consonants or words, or instances of nonnative intonation, caused them to change their minds. With Laura, comments focused on her general accent or her vowel quality. ${ }^{6}$ It appears that Julie and Laura have reached similar levels in performance. More often than not, they pass as native speakers. Only native speakers particularly sensitive to phonetic discrimination are able to notice nonnative qualities in their speech.

This task provided good examples of Julie's ability to manipulate EA discourse markers and pause fillers and to adapt them to the situation. For example, the recorded sample of her speech exhibited nativelike use of conventionalized language such as malh wi filfil wi kammuun ("salt and pepper and cumin," the traditional ordering of the three most common Egyptian spices). The recording also shows abundant use of discourse markers such as shufi ya sitti (similar to "well, let's see now") and wa eeh taani, ya rabbi (the equivalent of "good Lord, what else?") as well as pause fillers like ba'a ("well") and yanni (similar to "you know"). Laura's productions contained little of this conventionalized language.

\section{Accent Identification}

The second area of testing concerned our two subjects' ability to discriminate among accents of various dialects, a skill said to reflect nativelike competence (Long, 1990). Research has found that even proficient nonnative speakers are incapable of accurately discriminating accents as well as native speakers as young as age 10 (Scovel, 1981). Larsen-Freeman and Long (1991) comment that Scovel's results provide evidence in support of a sensitive period for accent identification in nonnative speakers.

A two-part procedure was employed in this section of the study. First, subjects were asked to discriminate among regional Arabic dialects presented on tape. There were seven recorded speech samples representing Libyan, Syrian, Palestinian, Kuwaiti, and Sudanese dialects as well as two regional Egyptian dialects. Julie and Laura were asked to rate these as Egyptian or non-Egyptian. This task is easier than many accent identification tasks because, in addition to pronunciation cues, morphosyntactic and lexical differences distinguish among dialects. Even so, it has been the authors' experience that nonnative speakers of Arabic typically have diffi- 
culty discriminating regional accents. For comparison, 11 judges from the previous task served as native-speaker controls.

Both Julie and Laura achieved $100 \%$ accuracy. It is interesting to note that two of the native-speaker judges attained only $85 \%$, misjudging the Libyan dialect because of its similarity to EA. These results show that Julie and Laura have excellent perceptive abilities, a prerequisite to achieving accent-free speech.

The second part of this task was more difficult. It measured the ability to discriminate among regional Egyptian dialects. Judges were asked to decide whether or not an accent was the Cairene variety of EA. The phonological properties that distinguish regional dialects in Egypt are very subtle. ${ }^{7}$ To make the task more difficult, one of the three speakers to be evaluated had moved to Cairo from another part of the country, so her dialect was not pure Cairene but a blend. Speaker 1 had a lower Egyptian accent, speaker 2 a Cairene accent, and speaker 3 a modified Cairene accent. Would Julie and Laura have the same intuitions toward these speakers as native Egyptians? Native-speaking judges on this task were the same as in the previous procedure.

Not all of the native-speaking judges were able to detect the non-Cairene features in speaker 3. Only 5 of the 11 identified her correctly. On this task Julie and Laura did not perform identically. Julie was closer to the native responses. Laura stated that she could detect no difference among the three accents in that they all sounded Cairene. She has not mastered the ability to discriminate among Egyptian accents. Julie, on the other hand, performed like the majority of the native speakers who were able to identify speaker 1 correctly as non-Cairene, but did not hear the subtle non-Cairene cues in speaker 3 .

From the preceding two measures, we have ascertained that Julie and Laura have indeed achieved similar levels of performance, though each through a different route, justifying further comparison of them.

\section{Grammatical Intuitions}

Having a good ear or being able to pass as a native speaker is not enough to qualify one as a native speaker. Nor does it give information on the characteristics of the learner's internal knowledge of the language. More important is an evaluation of the L2 learner's underlying linguistic competence. Very proficient learners may appear to be nativelike because they have no need to use constructions that manifest subtle points of the grammar unknown to them. To assess our two subjects' mental grammar, we administered a three-part procedure consisting of a translation task, a grammaticality judgment task, and a task to measure the interpretation of anaphora. The points tested are subtle and typically difficult for L2 learners of EA to master. ${ }^{8}$ They are derived from both principles of UG and rules specific to EA. The sentences used in this procedure were drawn from the research of Farghaly (1982) and Osman (1990) and from the authors' experience with L2 learners of EA.

Eleven native speakers were also evaluated for comparison. None of them served as judges in the previous two procedures. All of them were university graduates, five of them specializing in language, six in sciences. All were fluent in English, 
ensuring that they could follow directions and perform the translation task competently. Because Julie cannot read Arabic, the three tasks were presented on tape and administered to the test-takers individually to be answered at their convenience.

Translation task. First, we assessed our subjects' ability to translate selected constructs into Arabic. The sentences used each contained a rule-governed contrast related to relative clauses, yes/no questions, wh-questions, and conjoined NPs. All of the contrasts centered on rules that are very specialized to EA and are not directly translatable from English. The following is a sample item from the translation procedure together with a typical EA translation:

(1) Which book was it that Mona bought?

anhi kitaab illi mona ishtarit-u

which book that mona bought-it.

The 11 native and two near-native test-takers were given a list of 12 English sentences that they were asked to translate and record onto tape. They were instructed to give a spontaneous translation with minimal preplanning. Responses of Julie and Laura were scored first on their accuracy with respect to the contrasts tested, then on overall structure. Responses were considered correct if they matched a translation given by at least one native speaker for that item. In every respect Julie and Laura gave virtually flawless responses. They scored perfectly on the grammatical contrasts tested. The complexities of morphology were produced with $100 \%$ accuracy. There was little that was not nativelike elsewhere.

However, both Julie and Laura on one occasion used a preposition in a nonnative fashion, seemingly unaware of its obligatory deletion in certain contexts. In translating "went to the club," they both used raahit linnaadi instead of the native form raahit innaadi. The preposition 1 -, normally translated as "to," is obligatorily deleted whenever the meaning incorporates the concept "into."

In addition, Julie utilized the yes/no question particle incorrectly on one occasion when translating a relative clause with an emphatic subject.

(2) Nadia is the one that Ahmad saw.

NS form: nadya heyya illi ahmad shaf-ha nadia she that ahmad saw-her

Julie: heyya nadya illi ahmad shaf-ha Q nadya that ahmad saw-her

The third person singular pronouns huwwa (masculine) and heyya (feminine), in addition to their normal pronominal usage, can function as emphatic subject markers, in which case they follow the noun, or as optional indicators of yes/no questions, in which case they occur in sentence-initial position. Julie's word order here is that of a question rather than a statement. Apparently, she has not completely mastered the distribution of the pronominal forms huwwa and heyya as emphatic subject markers versus optional question markers, since in this example she placed the pronoun in the question marker position, rather than in the emphatic position. In 
personal conversation Julie acknowledged that she learned the use of these forms as question markers rather late and that she does not tend to use them as frequently as native speakers. ${ }^{9}$ However, in the other translation sentences, the word order distinction was correctly made for both functions.

Grammatical Judgment Task. The next procedure was a grammaticality judgment task where test-takers were asked to indicate on an answer sheet whether a recorded sentence was grammatical or ungrammatical. The sentences were read at a rapid rate with only a few seconds' pause between each. The task included $37 \mathrm{EA}$ sentences representing different syntactic structures. Test items were divided into two broad categories: those pertaining to constraints in UG and those that follow from language-particular rules of EA. Sentences in the second category may at some future date be shown to derive from principles of UG, but at present they are classified as adhering to language-particular restrictions. A list of the grammatical constructs used in this task and examples of each are given in the Appendix.

Before describing the individual constructs utilized, it is necessary to discuss some general features of EA. EA differs from standard Arabic and the other colloquial dialects in two important respects, both relating to word order. First, whereas standard Arabic and the other colloquial dialects have relatively free canonical word order, with one of them functioning as the unmarked variant, EA has a fixed word order of SVO. It does not allow deviations from this canonical order except in rare situations, not even for stylistic purposes.

The second difference concerns the formation of $w h$-questions. While standard Arabic and the other colloquial dialects form wh-questions by fronting the $w h$ phrase, EA typically forms them by leaving the wh-phrase in situ. This is most certainly the unmarked form of the $w h$-question and, for some speakers, the only form. In addition, optional $w h$-fronting can only occur with adverbial $w h$-phrases. Fronting is prohibited from NP slots, as the following sentences illustrate.

(3) a. samiir shaf miin

samir saw who

b. "miin samiir shaf

who samir saw

"Who did Samir see?"

(4) a. samiir "amal kidah leeh

samir did this why

b. leeh samiir 'amal kidah

why samir did this

"Why did Samir do this?"

There are some speakers who permit the fronting of wh-adverbials in direct questions but do not allow it as an option in indirect questions.

Turning to our test, the sentences relating to UG were drawn from the work of Osman (1990). They include violations of the complex NP constraint, the superiority constraint, and the binding principles (cf. Chomsky, 1981). These constraints and 
principles operate in English, also, but in a manner different from Arabic as a result of basic differences in the way movement rules operate in the two languages. Therefore, this task does not examine whether the L2 learner has been able to master aspects of UG inapplicable to the L1 or to reset specific parameters in the L2 but, rather, tests whether subjects have mastered the L2 sufficiently to realize that certain principles and constraints of UG apply differently.

Osman (1990) argues that since in situ wh-phrases do not violate subjacency, they do not adhere to island constraints. She finds a grammaticality contrast between sentences containing $w h$-phrases inside a complex NP and those where the wh-phrase has been fronted. Only the latter, which violate subjacency, are ungrammatical.

(5) a. fathi simi il-axbaar in samiir saafir ma' miin fathi heard the-news that samir left with whom

b. "ma' miin fathi simi" il-axbaar in samiir saafir with whom fathi heard the-news that samir left

"With whom did Fathi hear the news that Samir left?"

However, Wahba (1984) has argued that subjacency constraints are valid at both S-structure and logical form, following from the fact that she finds (5a) ungrammatical as well as (5b).

Another instance where the in situ $w h$-phrase contrasts with a fronted $w h$-phrase is in a sentence with multiple $w h$-phrases. Only the fronted $w h$-phrase results in ungrammaticality because of a violation of the superiority condition concerning movement and governance at logical form (Chomsky, 1981).

(6) a. miin xarag ma' miin who left with whom

b. 'ma' miin miin xarag with whom who left

"Who left with whom?"

However, if the subject $w h$-phrase is then shifted to a position following the verb, the sentence becomes grammatical because the shifted subject can now receive government.

(6) c. ma' miin xarag miin with whom left who

A third contrast derived from the principles of UG relates to the occurrence of overt proforms in relative clauses. These proforms are base generated to fill the argument position in the relative clause which is coreferential with the head noun. Osman (1990) notes that proforms, when occurring inside wh-constructions, are realized as resumptive pronominal clitics in all positions but subject, which is obligatorily null. This follows from the requirements of the binding theory (Chomsky, 
1981). An overt resumptive pronoun in the subject position of a relative clause will be locally bound, violating Principle $B$ of the binding theory. Resumptive pronouns filling other positions in the relative clause are not bound locally, and as a result no violation occurs. Therefore, sentences lacking resumptive pronouns in nonsubject position are ungrammatical, as are sentences with overt resumptive pronouns in subject position.

(7) a. ir-raagil illi ayyaan kallim-ak

the-man that sick called-you

b. *ir-raagil illi huwwa ayyan kallim-ak

the-man that he sick called-you

"The man who is sick called you."

(8) a. ir-raagil illi mona abilt-uh fi-l-maktaba mașri the-man that mona met-him in-the-library Egyptian

b. *ir-raagil illi mona abilt fi-l-maktaba mașri the-man that mona met in-the-library Egyptian

"The man that Mona met in the library is Egyptian."

The final contrast based on the constraints of UG pertains to the distribution of the question particle, which was described earlier. The question particle is limited to matrix clause questions, never occurring in embedded questions.

(9) a. hiyya mona irfit samiir raah feen

Q mona knew samir went where

"Did Mona know where Samir went?"

b. "mona irfit huwwa samiir raah feen mona knew Q samir went where

"Mona knew where Samir went."

It is not well understood what principle of UG restricts certain syntactic phenomena to matrix clause positions, but such structures are found in many of the world's languages. Korean, for example, has a large number of matrix clause particles. Structures restricted to the matrix clause appear to relate in some way to the speaker's disposition to the utterance. In the present case, the speaker is specifying that the utterance is a question. ${ }^{10}$

The language-particular constructs used on this task involve rules governing definiteness concord, the particulars of relativized structures, and word order possibilities related to conjoined NPs and questions. With respect to definiteness concord, EA adjectives and relative clauses must agree with their heads in definiteness. Typically, English speakers learning Arabic fail to observe this requirement by omitting the definite marker on definite adjectives or by inserting the relative marker, which is definite, on indefinite relative clauses.

There are two other interesting properties concerning relative structures. As already noted, questions cannot contain $w h$-phrases fronted from a nominal position. 
When a nominal $w$ h-phrase is focused in question-initial position, the remainder of the sentence takes the form of a relative clause. Thus, the complete question consists of only a question word and a relative clause. These are referred to as relativized questions.

(10) miin illi samiir kallim-u who that samir called-him "Who did Samir call?"

EA also manifests headless relative clauses where a normal definite relative clause can occur without a head or any internal changes.

(11) illi gaah kallim-ak that came called-you

"(The man) who came called you."

Both of the preceding constructs seem odd to English-speaking learners.

The remaining language-particular items involve word order in conjoined NPs and in questions. Conjoined NPs, where at least one member is a pronominal form, must obey a strict order that is different from that of English. The order is determined by the person and number of the pronoun and by whether it is joined to another pronoun or to a full NP. For example, in contrast to English, a first person pronoun will always precede a second person pronoun. Word order in questions was discussed earlier. Question words are normally left in situ. They can only be optionally fronted when they have adverbial function. However, it appears that some speakers do not readily accept rearranged question word order, especially in embedded questions.

The test contained five categories relating to language-particular constructs and four relating to UG, as represented in the Appendix. ${ }^{11}$ To evaluate the performance of Julie and Laura, we followed Coppieters (1987) in establishing a prototypical native norm corresponding to NS majority opinion on each item. ${ }^{12}$ We then determined where Julie and Laura diverged from the prototype. Table 1 presents the results on this task.

Table 1 indicates the majority NS grammaticality judgment for each test item and where Julie and Laura diverge from the majority response. A considerable range of variation was found in native-speaker responses, with agreement on particular items ranging from 55 to $100 \%$. As on all tasks involving grammaticality judgments, there were several sentences that were rejected by some of the native speakers for which we can find no explanation-for example, the $45 \%$ rejection of a headless relative clause (item 7). We were surprised to find that four NSs accepted a relative clause with an overt subject pronoun (item 11), contrary to the requirements of the binding theory in UG, and five accepted a question particle at the beginning of a subordinate question (item 20 ).

However, some of our results show where there is indeterminacy in the language and, therefore, genuine disagreement among native speakers. The sentence types involving wh-movement fall into this category. ${ }^{13}$ We found that a majority of NSs 
Table 1. NNS divergence ${ }^{a}$ from NS grammaticality judgments of languageparticular and UG-constrained constructs

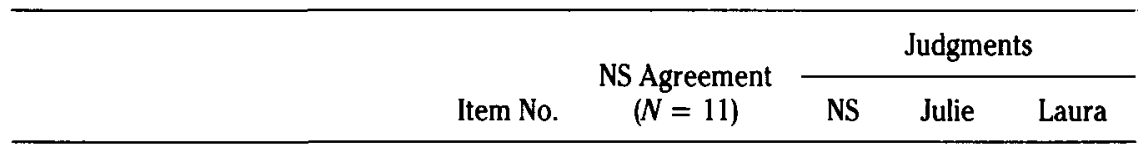

Language-particular constructs

\begin{tabular}{|c|c|c|c|c|}
\hline Definiteness concord & $\begin{array}{r}3 \\
33 \\
36 \\
12 \\
19 \\
6 \\
1 \\
14\end{array}$ & $\begin{array}{r}100 \% \\
100 \% \\
100 \% \\
91 \% \\
91 \% \\
82 \% \\
82 \% \\
73 \%\end{array}$ & $\begin{array}{l}r \\
x \\
x \\
x \\
x \\
x \\
x\end{array}$ & $\boldsymbol{r}$ \\
\hline Relativized questions & $\begin{array}{l}35 \\
17 \\
22 \\
21 \\
26\end{array}$ & $\begin{array}{r}100 \% \\
91 \% \\
91 \% \\
73 \% \\
64 \%\end{array}$ & $\begin{array}{l}x \\
x \\
x \\
r \\
x\end{array}$ & \\
\hline Headless relative clauses & $\begin{array}{l}9 \\
7\end{array}$ & $\begin{array}{l}73 \% \\
55 \%\end{array}$ & r & \\
\hline Conjoined NP word order & $\begin{array}{r}24 \\
8 \\
28 \\
4 \\
27\end{array}$ & $\begin{array}{r}100 \% \\
73 \% \\
73 \% \\
73 \% \\
55 \%\end{array}$ & $\begin{array}{l}r \\
x \\
x \\
r\end{array}$ & \\
\hline Variable word order in questions & $\begin{array}{r}32 \\
25 \\
37 \\
18 \\
2\end{array}$ & $\begin{array}{r}100 \% \\
100 \% \\
91 \% \\
73 \% \\
55 \%\end{array}$ & $\begin{array}{r}r \\
-2 \\
x\end{array}$ & $\begin{array}{l}\mathbf{X} \\
\mathbf{x}\end{array}$ \\
\hline
\end{tabular}

UG-constrained constructs

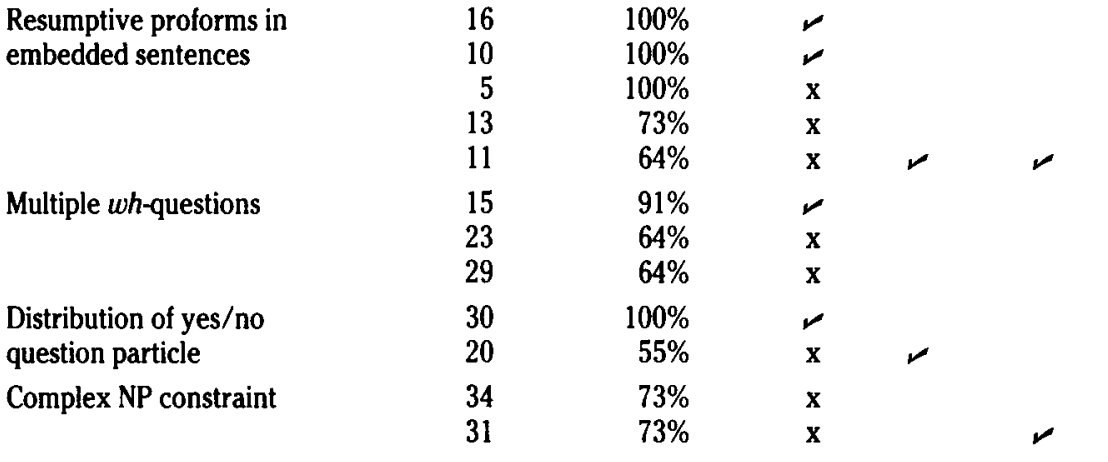

Note: $r=$ acceptance of item as grammatical; $x=$ rejection of item as ungrammatical.

"Only those responses by Julie and Laura that diverge from the majority NS response are indicated. 
rejected movement of an adverbial $w h$-phrase originating inside an embedded question. Eight disallowed movement to the beginning of the subordinate sentence to create an indirect question (item 18), while six rejected movement to the beginning of the matrix sentence to create a direct question (item 2). It appears that NSs are more rigid in their rejection of marked word order involving subordinate whphrases. Seven NSs judged as ungrammatical sentences with multiple wh-phrases like (7c), above, where the second wh-phrase is tronted and the subject is shifted to after the verb (items 23 and 29). The judgments of ungrammaticality on these wh-movement items conflict with the intuitions of Osman (1990); however, in each case there is a sizable minority who agree with her intuitions. Since there was considerable variability in response patterns among native speakers on sentences involving wh-movement, we questioned NSs individually about their degree of certainty on these items. None of the native speakers changed their minds or even hesitated in reaffirming their intuitions.

We found one other disagreement with the judgments of Osman (1990). A majority ( 8 of the 11 ) rejected a sentence like (5a), above, containing a complex NP followed by a wh-phrase left in situ (item 34). These speakers agreed with Wahba (1984) that subjacency is valid at both S-structure and logical form.

As can be seen in Table 1, the performance of both Julie and Laura was comparable to that of native speakers in the majority of cases. The divergence that did occur was exhibited, for the most part, on sentences with less than $80 \%$ native-speaker agreement, indicating that at least three native speakers shared their opinion. In general, disagreements consisted of judging ungrammatical sentences as grammatical.

It is necessary to examine the particular items where the two subjects deviated from the NS majority response. Both Julie and Laura accepted an ungrammatical sentence where the adjective did not agree in definiteness with the head but correctly rejected another of the same type (items 14 and 19). With conjoined NP structures, Laura, but not Julie, accepted all the variants as grammatical, possibly not aware of the restrictions governing the ordering of nouns and pronouns in coordinate NPs, where, unlike English, a pronominal form must precede a full NP and first person pronouns precede those of the second person.

Both Julie and Laura deviated from the NS norm in their assessment of optional word order variations in questions. Native speakers allowed more scrambling possibilities. For example, unlike $91 \%$ of the native speakers, they rejected the following question with a fronted question word and subject/verb inversion (item 37) as ungrammatical:

(12) imta saafrit nadya

when left nadia

"When did Nadia leave?"

Julie, in particular, seemed to reject variable word order in questions, insisting on in situ $w h$-phrases, the unmarked word order, throughout the test.

Both Julie and Laura, like four of the native speakers, allowed an overt subject 
pronoun in a relative clause, in contradiction to the requirements of the binding theory (item 11). Julie, but not Laura, accepted the question particle at the beginning of an embedded question (item 20), similar to five of the native speakers, but in violation of structure-preserving constraint. Laura agreed with Osman's intuitions and the minority in allowing a wh-phrase in situ inside a complex NP (item 31). Julie, like the majority, rejected it.

In general, both Julie and Laura performed surprisingly well. Of the total of 37 sentences, Julie had divergent judgments on five sentences, Laura on six. Two of Julie's five divergent judgments consisted of rejecting optional variants; the other three were failures to reject sentences the majority judged ungrammatical. Laura rejected one optional variant and accepted as grammatical five sentences judged ungrammatical by the majority. Their deviations occurred on both languageparticular and UG-derived constructs. Our data do not allow us to conclude that the two learners were unable to apply the principles of UG to L2 data since each deviation from a UG-derived constraint was shared by many of the NSs. We can assume, therefore, that both Julie and Laura share intuitions with native speakers on the majority of the syntactic points tested. However, it is important to note that though many native speakers deviated from the norm in their judgments as often as Julie and Laura, none exhibited patterns (e.g., on conjoined NP word order, for Laura, or on optional word order in questions, for Julie) but deviated in a more random manner. Additional testing is needed to provide a better comparison of the internal organization of the learners' grammars with the structural organization of native grammars.

The Interpretation of Anaphora. The third task in this part of the study dealt with the interpretation of anaphora, based on Farghaly's (1982) discussion of the disambiguating function of overt subject pronouns in embedded clauses. An example of this function is illustrated in the following pair of sentences.

(13) a. nadya shaafit mona lamma daxalit il-ooda nadia saw mona when entered the-room.

b. nadya shaafit mona lamma heyya daxalit il-ooda nadia saw mona when she entered the-room

"Nadia saw Mona when (she) entered the room."

The absence of an overt subject pronoun in (13a) makes the preferred interpretation one that assigns the adjacent NP (Mona) as the subject of the verb daxalit. In contrast, the overt subject pronoun in (13b) marks disjoint reference with the adjacent NP (Mona) crossing to the more remote NP (Nadia) as the preferred antecedent.

The anaphora task included 18 recorded sentences. Each sentence contained one to three lexical NPs followed by an embedded clause with either a null or overt subject pronoun. The sentences represented the different syntactic categories shown in Table 2. The test-takers were asked to respond to the question "Who did X?" where did $X$ is the predicate of the embedded clause. This procedure enabled the authors to determine what reference test-takers were assigning. Answers could be 
Table 2. NNS divergence from NS preferred interpretation of anaphora in three syntactic categories

\begin{tabular}{|c|c|c|c|c|}
\hline \multirow[b]{2}{*}{ Syntactic Category } & \multirow[b]{2}{*}{ Item No. } & \multirow{2}{*}{$\begin{array}{l}\text { NS Agreement } \\
(N=11)\end{array}$} & \multicolumn{2}{|c|}{ NNS Divergence } \\
\hline & & & Julie & Laura \\
\hline \multicolumn{5}{|l|}{ Conjoined sentence } \\
\hline Adjacent reference ${ }^{a}$ & 2 & $100 \%$ & & \\
\hline Remote reference & 8 & $100 \%$ & & \\
\hline \multicolumn{5}{|c|}{ Backward pronominalization } \\
\hline Adjacent reference & 18 & $91 \%$ & & \\
\hline Remote reference & 16 & $100 \%$ & & \\
\hline \multicolumn{5}{|l|}{ Relative clause } \\
\hline \multirow[t]{5}{*}{ Adjacent reference } & 1 & $73 \%$ & $\mathbf{x}$ & \\
\hline & 3 & $91 \%$ & & \\
\hline & 5 & $64 \%$ & & \\
\hline & 7 & $100 \%$ & & \\
\hline & 10 & $91 \%$ & & \\
\hline \multirow[t]{5}{*}{ Remote reference } & 6 & $64 \%$ & $\mathbf{x}$ & \\
\hline & 11 & $73 \%$ & $\mathbf{x}$ & \\
\hline & 13 & $91 \%$ & $\mathrm{x}$ & \\
\hline & 14 & $82 \%$ & $\mathrm{x}$ & \\
\hline & 15 & $82 \%$ & $\mathbf{x}$ & \\
\hline
\end{tabular}

Note: $\mathrm{x}=$ NNS divergence from majority NS interpretation of an item.

"Sentences that received a NS preferred interpretation of adjacent reference contained embedded null subjects. Those that received a preferred interpretation of remote reference contained embedded overt pronominal subjects.

written in either Arabic script, transliteration, or English translation. Table 2 gives the results on this task.

Here one can see a difference in the performance of Julie and Laura. Laura interprets reference in the same manner as the NS norm. Julie, on the other hand, has acquired the distinction between overt and null proforms in coordinate and preposed subordinate structures; however, when the anaphora occurs inside a relative clause, she does not distinguish between the two. She consistently assigned adjacent reference, as the following example (item 13) illustrates.

(14) ahmad ishtara il-fustaan li-t-bint illi inta ruht li-s-sit illi heyya za"alit-ha Ahmad bought the-dress for-the-girl that you went to-the-lady that she angered-her "Ahmad bought the dress for the girl that you went to the lady that she angered (her)."

(miin za"al miin)

(who angered who)

"Who angered whom?"

The preferred NS interpretation was "The girl angered the lady," whereas Julie answered that "The lady angered the girl."

The sentences containing relative clauses were deliberately complex, so even native speakers found them difficult to process. There was substantially more variability among native speakers in their interpretation of anaphora in relative clauses than in conjoined sentences or with backward pronominalization. Julie indicated 
that she had considerable difficulty keeping track of NPs in the relative clause structures. It may be that her divergence on these items is due to problems in processing these complex sentences, rather than difficulty in assigning reference. To ascertain which was the case, one would need to assess her performance on sentences of this type that are less complex. In any case, her performance diverged from that of native speakers.

This task deals with discourse semantics and is the only one that consistently distinguishes Julie from native speakers. It is interesting that Coppieters (1987) also found that his near-native speakers gave more incorrect hypotheses on discourse semantic constructs than on sentence-level syntax. Perhaps additional testing in this area will reveal domains where Julie's grammar is incomplete.

It appears that these two learners, one tutored and one untutored, have achieved similar grammatical competence in EA. There seems to be little that distinguishes a successful learner with formal instruction from one without. This appears to contrast with typical L2 learners who do not achieve nativelike proficiency. In such cases, contrasts can be made between the tutored and untutored learner. Long (1987), after reviewing the research comparing instructed and naturalistic learners, concluded that, in general, instructed learners reach higher levels of proficiency than naturalistic learners and produce more accurate morphology and syntax. Learners from any learning background who achieve nativelike levels of L2 are rare. For exceptional learners, it seems that formal instruction does not give rise to different results. The differences noted between Julie and Laura were minor. Julie has better perceptual skills for accent recognition. Laura is unaware of coordinate NP word order restrictions that Julie has mastered. Julie is more rigid with regard to optional word order possibilities and has more difficulty with one type of anaphoric reference.

Is Julie (or for that matter Laura) the exception to the critical period hypothesis? They both seem very close to a native level of proficiency in perceptual abilities, production skills, and underlying linguistic competence. However, if it is in the domain of discourse syntax and semantics that nonnative speakers fail to reach native norms, then more testing of both our subjects needs to be done in this area before we can evaluate how nativelike their internalized grammar is.

\section{ACCOUNTING FOR JULIE'S SUCCESS}

One question remains to be answered: What accounts for Julie's phenomenal success? ${ }^{14}$ Untutored language learners typically fossilize at the early stages of syntactic and morphological development (Higgs \& Clifford, 1982). A typical example is Wes, described in Schmidt (1983). Wes has discourse fluency, but his language has minimal accuracy in grammatical structure. ${ }^{15}$ Other than in his ultimate attainment, Wes resembles Julie. He is socially outgoing and obtains abundant comprehensible input and error feedback. He employs the learning strategies of the good language learner. These characteristics he shares with Julie; yet Julie was successful, Wes was not. There seem to be two important differences between them relevant to their ultimate attainment. 
First, Julie, from the very beginning, consciously manipulated the grammatical structure of the language. She paid attention to morphological variation because she saw it as necessary for successful communication. Entries in her copy book were reviewed on a regular basis. When she received error feedback, she made mental note of the information it provided. Certainly she was not consciously aware of every aspect of grammar that she internalized; however, she did notice redundant morphological structure. Her attitude toward grammar was that it needed to be mastered correctly.

Wes had a different attitude toward structure, one that frequently characterizes naturalistic language learners. He normally ignored grammatical corrections from native speakers. His primary concern was the content of the message, and he employed a number of communication strategies to help him when his inadequate syntax led to misunderstandings. Why Wes ignored grammatical structure is not clear. It could be because he believed it to be unimportant, or perhaps it was too difficult for him to control. But the fact remains, he did not consciously note grammatical distinctions and manipulate them; therefore, he did not acquire them.

Many researchers have suggested that adult language learners need conscious attention to form from the earliest stages. Schmidt (1983) hypothesizes that this is what differentiates the child language learner from the adult: "Adults seem to have lost the still mysterious ability of children to acquire the grammatical forms of language while apparently not paying attention to them" (p. 172). Schmidt (1990) further elaborates this position. He concludes that conscious awareness of form is necessary for adults to acquire the redundant grammatical features of language. Our research gives support to these observations.

But even with attention to form, most L2 learners do not achieve nativelike proficiency. We believe an additional factor is responsible for Julie's success: talent in learning languages. Language learning talent is hypothesized to be associated with unusual brain organization where a greater proportion of cortex is devoted to language (Novoa et al., 1988; Obler, 1989; Schneiderman \& Desmarais, 1988a). Such atypical brain organization allows the learner to be more cognitively flexible in processing L2 input and ultimately organizing it into a system.

Language learning talent is considered to be an innate, inherited trait, associated with inherited characteristics belonging to the Geschwind cluster such as lefthandedness, twinning, and allergies, among others (Obler, 1989). Julie reports that all of these traits are present in her family. Her paternal grandmother is a twin, left-handedness runs in her father's family (she, herself, is left-handed), and she has very sensitive skin and skin allergies. Furthermore, talent in one area is usually coupled with a corresponding weakness in another cognitive area (Obler, 1989). Julie reports that her performance in math or anything that involves manipulating numbers is dismal. She fits very well the neuropsychological profile associated with unusual cognitive ability. ${ }^{16}$

Skehan (1986) notes that aptitude for L2 correlates with speed in Ll acquisition. Findings indicate that learners who displayed a superior aptitude for L2 acquisition were also those who made the most rapid progress in the acquisition of their L1. 
Julie reports that she was precocious in $\mathrm{L} 1$ acquisition. Her mother indicates that she spoke in full sentences at 18 months. Julie remembers that at age 2 she was able to imitate characters from the radio and was frequently called upon to perform before guests. ${ }^{17}$ Her rapid $\mathrm{Ll}$ acquisition is a further indication that her language learning mechanism is in some way exceptional.

The language learning skills that have been shown to characterize the talented language learner are superior associative memory and the ability to master new codes as well as an ear for phonetic cues (Novoa et al., 1988; Obler, 1989; Schneiderman \& Desmarais, 1988b). These are the same traits associated with language learning aptitude (Skehan, 1993). Julie manifests these abilities. She acquires new vocabulary easily, always did well in grammar in her Latin courses, and has a talent for mimicking other accents of English. All signs point to Julie having the neuropsychological brain organization that typifies talented language learners. We hypothesize that her talent has had two effects. It has given her the ability to perceive the linguistically significant contrasts in L2 input, even those that were only implicitly noted (cf. Schmidt, 1990), and it has enabled her to organize the information obtained into a nativelike L2 grammar, independent of the L1 grammar.

We would further like to hypothesize that any apparent exceptions to the $\mathrm{CPH}$ will manifest some aspect of the neuropsychological profile that characterizes language learning talent, a position also advocated by Obler (1989) and Schneiderman and Desmarais (1988a, 1988b). ${ }^{18}$ However, how the talented brain acquires language in comparison with the normal brain remains a mystery.

Do talented learners still have access to the language acquisition system that allows for $\mathrm{L} 1$ acquisition in all humans, a system that has perhaps become inaccessible to normal L2 learners at the close of the critical period? Or do talented learners use a different neuropsychological structure to acquire a second language as adults? A study by Smith and Tsimpli (1991) appears to advocate the second position. Their subject is a "savant" linguist who, though mentally handicapped, achieved a high degree of fluency in 16 languages as an adult. They argue that he did not follow the course of $\mathrm{L} 1$ acquisition in mastering these languages but, rather, learned them as L2s. They arrive at this conclusion after determining that he did not reset specific parameters in his L2 acquisition of Greek.

Whatever the answer to the question posed earlier, we are left with the following observation: If there is a critical period for language acquisition, it is because some neurocognitive change has occurred in the brain as it matured; if there are exceptions to the critical period, this change does not happen in the usual way. It remains to be answered whether this difference implies allowing an existing system to continue to function or whether an alternative system subsumes the role of language acquisition. However, even if language learning talent involves continued use of the $\mathrm{L} 1$ acquisition system in adulthood, talented adult language learning differs from child $L 1$ acquisition in one very significant respect. For some yet to be discovered reason, talented adults, unlike children, appear to require conscious attention to grammatical form.

(Received 4 June 1993) 


\section{NOTES}

1. Several recent studies have investigated the extent to which talented adult language learners have acquired the grammatical competence of native speakers with respect to selected remote constructions in the L2 grammar. In particular, see the work of Birdsong (1992), Coppieters (1987), Smith and Tsimpli (1991), and Sorace (1993).

2. Julie had no access to English materials in this early period because her belongings were tied up in customs until her husband could clear them. Also, being new to Cairo, she had no idea where one might purchase printed material in English.

3. Corroborating Julie's own memory of this period, Egyptian colleagues of the authors who interacted with her in these early years recollect her nativelike ability at that point.

4. A difference was noted in Julie's and Laura's approaches to this procedure. As soon as Julie was informed of the nature of the task, she spoke spontaneously for about $3 \mathrm{~min}$ with no prior preparation. Laura, on the other hand, spoke for about 1 min, referring frequently to points she had previously jotted down.

5. This evaluation procedure is more stringent than those usuaily employed to judge L2 performance, where raters are simply asked to decide whether the voices are native speakers of any dialect of the language (Neufeld, 1979; Schneiderman \& Desmarais, 1988b).

6 . In the case of Julie, judges did not specify the same words or consonants as indicators of nonnativeness. The reasons for their decisions varied from judge to judge. On the other hand, their assessments of Laura when judged as nonnative were more consistent.

7. In general, the differences result from differences in intonation contours, timing of vowels, and rhythm. There are also certain differences in stress patterns and the articulation of selected consonants and vowels. The Cairene dialect is considered to be "softer" by Egyptian speakers.

8. The difficulty is corroborated through informal conversations with $\mathrm{L} 2$ learners residing in Cairo, through information given to the authors by Arabic L2 instructors, and by the first-hand experience of the first author, who has tried for many years to master EA.

9. By contrast, the first author, after $4 \frac{11}{2}$ years of speaking EA as a second language, had never even noticed the question marker and was quite surprised when its existence was pointed out to her by her colleagues. This is most certainly due to the fact that it is extremely reduced in fast speech pronunciation, to the point where it is barely perceptible.

10. Notice that English has a structure which is restricted to the matrix clause that is used to express wishes. Thus, sentence (a) below is grammatical, whereas (b) is not.

a. May you arrive safely.

b. *John said that may you arrive safely.

The Romance languages also have volitive structures introduced by que that are restricted to matrix clauses.

c. que Dieu vous bénisse

may God you bless

"May God bless you."

d. *il dit que Dieu vous bénisse

he said that God you bless

"He said that may God bless you."

We are indebted to Joe Emonds for pointing this out to us.

11. The number of items in a category was a function of the syntactic requirements of the construct. For example, definiteness concord required eight test items: a grammatical and ungrammatical exemplar of both definite and indefinite adjectives and relative clauses.

12. In approaching grammaticality in this way, several test sentences considered grammatical according to theory were marked ungrammatical in Table 1, after being rejected by a majority of native speakers. An example of this is sentence (5a), one of the complex NP constraint sentences. We expected this sentence to be considered grammatical by native speakers, but the majority judged it ungrammatical. All sentences judged contrary to expectations are discussed in the text.

13. One anonymous reviewer suggested that the mixed judgments may be the result of the influence of standard Arabic, which allows movement in questions. However, Egyptians tend to be very firm about the form of their dialect and, if anything, appear to modify the standard using rules from colloquial. After scoring the tests, we questioned the NSs as to their degree of certainty in their answers for items involving wh-movement. We found that speakers were very firm about their intuitions on these items. 
14. We will not try to account for Laura's success in this paper since exceptional tutored learners like Laura have already been discussed extensively in the literature (cf. Birdsong, 1992; Coppieters, 1987; Novoa, Fein, \& Obler, 1988; Schneiderman \& Desmarais, 1988b; Sorace, 1993). This is not to say that talented L2 learning with instruction is a well-understood phenomenon; it is just that our data offer no new insights to augment the discussions already provided.

15. At the time of Schmidt's study, Wes had been learning English for only 5 years. One might conclude that he is not a fair comparison with Julie. However, after 15 years of interacting in English, his grammar appears to be at the same stage of fossilization (R. Schmidt, personal communication, 1992).

16. Though we are not accounting for Laura's exceptional ability in this discussion, it is interesting to note that she does not seem to manifest the physical characteristics of the Geschwind cluster. She has no left-handedness, twinning, or allergies in her family. She does not recall being particularly good or bad in math, art, or music.

17. Julie's recollection of her L1 acquisition was confirmed by her mother, who was living in Cairo at the time of the study.

18. This claim may have to be modified in light of the fact that Laura apparently does not exhibit aspects of this profile. Further study of Laura and a better understanding of exceptional language learners are needed.

\section{REFERENCES}

Birdsong, D. (1992). Ultimate attainment in second language acquisition. Language, 68, 706-755.

Bley-Vroman, R. (1990). The logical problem of foreign language learning. Linguistic Analysis, $20,3-49$.

Carroll, J. B. (1965). The prediction of success in foreign language training. In R. Glaser (Ed.), Training, research and education (pp. 87-136). New York: Wiley.

Carroll, J. B. (1991). Cognitive abilities in foreign language aptitude. In T. Perry \& C. Stansfield (Eds.), Language aptitude reconsidered (pp. 11-27). Englewood Clifts, NJ: Prentice-Hall Regents.

Chomsky, N. (1981). Lectures on government and binding. Dordrecht: Foris.

Clahsen, H. (1990). The comparative study of first and second language development. Studies in Second Language Acquisition, 12, 135-154.

Coppieters, R. (1987). Competence differences between natives and fluent non-native speakers. Language, $63,544-573$.

Farghaly, A. (1982). Subject pronoun deletion rule in Egyptian Arabic. In S. Gamal \& R. Bowers (Eds.), Discourse analysis: Theory and application. Proceedings of the Second National Symposium on Linguistics and English Language Training (pp. 60-69). Cairo: Center for Developing English Language Teaching, Ain Shams University.

Felix, S. (1985). More evidence on competing cognitive systems. Second Language Research, 1, 47-72.

Flege, J. (1987). A critical period for learning to pronounce foreign languages? Applied Linguistics, 8, 162177.

Flynn, S. (1989). The role of the head-initial/head-final parameter in the acquisition of English relative clauses by adult Spanish and Japanese speakers. In S. Gass \& J. Schachter (Eds.), Linguistic perspectives on second language acquisition (pp. 306-326). Cambridge: Cambridge University Press.

Flynn, S., \& Manuel, S. (1991). Age-dependent effects in language acquisition: 'Critical period' hypotheses. In L. Eubank (Ed.), Point-counterpoint: Universal Grammar in second language (pp. 117-145). Amsterdam: John Benjamins.

Genesee, F. (1988). Neuropsychology and second language acquisition. In L. Beebe (Ed.), Issues in second language acquisition: Multiple perspectives (pp. 79-112). Cambridge, MA: Newbury House.

Higgs, T., \& Clifford, R. (1982). The push toward communication. In Higgs, T. (Ed.), Curriculum, competence, and the foreign language teacher (pp. 57-79). Skokie, IL: National Textbook.

Johnson, J., \& Newport, E. (1989). Critical period effects in second language learning: The influence of maturational state on the acquisition of ESL. Cognitive Psychology, 21, 60-99.

Krashen, S. (1982). Principles and practice in second language acquisition. New York: Pergamon Press.

Larsen-Freeman, D., \& Long, M. (1991). An introduction to second language acquisition research. London: Longman.

Lenneberg, E. (1967). Biological foundations of language. New York: John Wiley.

Long, M. (1987). Instructed interlanguage development. In L. Beebe (Ed.), Issues in second language acquisition (pp. 115-141). New York: Newbury House.

Long, M. (1990). Maturational constraints on language development. Studies in Second Language Acquisition, $12,251-285$.

Neufeld, G. (1978). On the acquisition of prosodic and articulatory features in adult language learning. Canadian Modern Language Review, 34, 163-174. 
Neufeld, G. (1979). Towards a theory of language learning ability. Language Learning, 29, 227-241.

Novoa, L., Fein, D., \& Obler, L. (1988). Talent in foreign languages: A case study. In L. Obler \& D. Fein (Eds.), The exceptional brain: The neuropsychology of talent and special abilities (pp. 294-302). New York: Guilford Press.

Obler, L. (1989). Exceptional second language learners. In S. Gass, C. Madden, D. Preston, \& L. Selinker (Eds.), Variation in second language acquisition: Psycholinguistic issues (pp. 141-159). Clezedon, UK: Multilingual Matters.

Osman, M. (1990). The syntax and logical form of wh-interrogatives in Cairene Egyptian Arabic. Unpublished doctoral dissertation, University of Washington, Seattle.

Oyama, S. (1976). A sensitive period in the acquisition of a non-native phonological system. Journal of Psycholinguistic Research, 5, 261-285.

Patkowski, M. (1980). The sensitive period for acquisition of syntax in a second language. Language learning, $30,449-472$.

Penfield, W., \& Roberts, L. (1959). Speech and brain mechanisms. New York: Atheneum Press.

Scarcella, R. (1983). Discourse accent in second language performance. In S. Gass \& L. Selinker (Eds.), Language transfer and language learning (pp. 306-326). Rowley, MA: Newbury House.

Schachter, J. (1989). Testing a proposed universal. In S. Gass \& J. Schachter (Eds.), Linguistic perspectives on second language acquisition (pp. 73-88). Cambridge: Cambridge University Press.

Schmidt, R. (1983). Interaction, acculturation, and the acquisition of communicative competence: A case study of an adult. In N. Wolfson \& E. Judd (Eds.), Sociolinguistics and language acquisition (pp. 137174). Rowley, MA: Newbury House.

Schmidt, R. (1990). The role of consciousness in second language learning. Applied Linguistics, 11, 129-158.

Schneiderman, E., \& Desmarais, C. (1988a). A neuropsychological substrate for talent in second language acquisition. In L. Obler \& D. Fein (Eds.), The exceptional brain: Neuropsychology of talent and special abilities (pp. 103-126). New York: Guilford Press.

Schneiderman, E., \& Desmarais, C. (1988b). The talented language learner: Some preliminary findings. Second Language Research, 4, 91-109.

Scovel, T. (1981). The recognition of foreign accents in English and its implications for psycholinguistic theories of language acquisition. In J. Scavard \& L. Laforge (Eds.), Proceedings of the Fifth Congress of AlLA (pp. 389-401). Laval, Canada: University of Laval Press.

Skehan, P. (1986). The role of foreign language aptitude in a model of school learning. Language Testing, 3 , 188-221.

Skehan, P. (1993). Cognitive abilities and language acquisition. Unpublished manuscript, Thames Valley University, London.

Smith, N., \& Tsimpli, I. (1991). Linguistic modularity? A case study of a 'Savant' linguist. Lingua, 84, 315-351.

Sorace, A. (1993). Incomplete vs. divergent representations of unaccusativity in non-native grammars of Italian. Second Language Research, 9, 22-48.

Wahba, W. (1984). Wh-constructions in Egyptian Arabic. Unpublished doctoral dissertation, University of Illinois.

White, L. (1989). The principle of adjacency in second language acquisition: Do L2 learners observe the subset principle? In S. Gass \& J. Schachter (Eds.), Linguistic perspectives on second language acquisition (pp. 134-158). Cambridge: Cambridge University Press.

White, L. (1992). On triggering data in L2 acquisition: A reply to Schwartz and Gibala-Ryzak. Second Language Research, 8, 120-137.

Yorio, C. (1989). Idiomaticity as an indicator of second language proficiency. In K. Hyltenstam \& L. Obler (Eds.), Bilingualism across the lifespan (pp. 55-72). Cambridge: Cambridge University Press. 


\section{APPENDIX}

\section{EXAMPLES OF CONSTRUCTS USED ON GRAMMATICALITY JUDGMENT TASK}

\section{Language Particular}

Definiteness Concord

aabilt ir-raagil il-mashhur

met-I the-man the-famous

*aabilt ir-raagil mashhur met-I the-man famous

"I met the famous man."

\section{Relativized Questions}

miin illi ahmad aabl-u who that ahmad met-him

"miin ahmad aabl-u

who ahmad met-him

"Who is it that Ahmad met?"

\section{Headless Relative Clauses}

illi bint-u gat muhandes kibiir that girl-his came engineer great

"(The one) whose daughter came is a great engineer."

Conjoined NP Word Order

nadya raahit ma'aah huwwa wi 'ali in-naadi nadia went with-him him and ali the-club

*nadya raahit ma"ali wi ma' aah in-naadi nadia went with ali and with-him the-club

"Nadia went with Ali and him to the club."

Variable Word Order in Questions

heyya samiira ti'raf mona raahit feen

$Q \quad$ samira know mona went where

*heyya samiira ti'raf feen raahit mona

Q samira know where went mona

"Does Samira know where Mona went?"

\section{UG Constrained}

Resumptive Proforms in Embedded Sentences

il-bint di min iș-şa'b it-tahakkum fii-ha the-girl this from the-difficult the-control in-her 
*il-bint di min is-sa'b it-tahakkum fii the-girl this from the-difficult the-control in

"This girl is difficult to control."

\section{Multiple Wh-Questions}

miin xarag ma' mïn

who left with who

${ }^{*}$ ma' miin xarag miin

with who left who

"Who left with whom?"

Yes/No Question Particle

heyya nadya ti'raf ahmad gaab il-kutub mineen

Q nadia know ahmad got the-book from-where

*nadya ti'raf huwwa ahmad gaab il-kutub min-een nadia know $Q$ ahmad got the-book from-where

"Does Nadia know where Ahmad got the book from?"

\section{Complex NP Constraint}

ma' miin 'ali simi' in mona saafrit

with who ali heard that mona traveled

"ma' miin 'ali simi' il-axbaar in mona saafrit

with who ali heard the-news that mona traveled

"With whom did Ali hear (the news) that Mona traveled?" 